\title{
ARQUIVO MORTO OU CENTRO DE HISTÓRIA? UM BREVE ESTUDO SOBRE A IMPORTÂNCIA DO COTIDIANO ESCOLAR PARA A PESQUISA
}

\author{
Maria Helena Alves da Silva ${ }^{1}$ \\ Maria Aparecida Chaves Ribeiro Papali ${ }^{2}$ \\ Valéria Regina Zanetti ${ }^{3}$
}

\begin{abstract}
Resumo: Embora os documentos sejam percebidos na sua importância legal e institucional ao garantirem um fluxo contínuo de informações, os documentos relacionados ao cotidiano escolar, como planos de aula, diários de classe e cadernos de alunos são muitas vezes os primeiros a serem descartados. Este trabalho tem como objetivo explorar as definições de "Arquivo Morto" e "Centro de Memória", trabalhando como a documentação história de uma Instituição de Educação como a UNIVAP - Universidade do Vale do Paraíba, precisa ser mantida e preservada em um Centro de História tal como o CEHVAP - Centro de História da UNIVAP, de forma a mantermos o contato histórico com o dia-a-dia das relações e pensamentos de um período. Para escrevermos esse artigo, utilizamos da metodologia de pesquisa de aspecto qualitativo, em que investigamos livros, artigos e documentos históricos relevantes para a nossa temática, utilizando de autores que tratassem sobre o cotidiano escolar, a importância de acervos institucionais e a relevância de tratar sobre o 'arquivo morto'.
\end{abstract}

Palavras-chave: Centro de história; Arquivo morto; Cotidiano escolar.

\footnotetext{
1 Graduada em História, mestranda do programa de Planejamento Urbano e Regional da Universidade do Vale do Paraíba, Brasil. E-mail: cehvap@univap.br.

2 UNIVAP/Faculdade de Educação e Artes, Brasil. E-mail: papali@univap.br.

3 UNIVAP/Faculdade de Educação e Artes, Brasil. E-mail: zanetti@univap.br.
} 